\title{
Service Quality Perceptions of Domestic Airline Consumers in India - An Emperical Study
}

\author{
Malyadri $\mathbf{P}^{1^{\star}}$ and Satyanarayana $\mathbf{P}^{2}$ \\ ${ }^{1}$ Principal, Government, Degree College, Patancheru, Osmania University, Hyderabad, India
}

${ }^{2}$ Ph.D.Research Scholar, Department of Mgmt. Studies, Dravidian University, Kuppam, India

*Corresponding author: Malyadri, Principal, Government, Degree College, Patancheru, Osmania University, Hyderabad, India, Tel: +91-9440064866; E-mail: drpm16@gmail.com

Received date: September 06, 2014; Accepted date: October 09, 2014; Published date: October 16, 2014

Copyright: ( 2014 Malyadri P, et al. This is an open-access article distributed under the terms of the Creative Commons Attribution License, which permits unrestricted use, distribution, and reproduction in any medium, provided the original author and source are credited.

\section{Abstract}

Services are intangible by nature. Services are heterogeneous and airline services are no exception to this. Services provided inside aircraft are intangible and highly variable. Airline services are highly personalized. The airline product is a highly perishable one. The airliner companies Management's believe that, they are providing committed quality of service to the customers, but in the point of view of the customer, airliners' are lacking in quality service. Airliners' lacks in awareness about service quality and are not aware that giving better service to the customers helps in better company performances In view of the above there is ample scope of research in the area of Service offerings with a view of Customer Service in domestic airlines arena which has potential research possibilities in Indian Airlines Industry.

This paper showcases some of the findings in this direction with respect to Indian Domestic Airline Industry. It highlights to examine how the customers are feeling about the company's services and its service quality. The two main constituents are the "quality expected or experienced" and "quality perceived" by the customer. As study on these variables, the Airlines best conforming to customers' perceptions are Kingfisher Airlines and Indigo Airlines.

\section{JEL Classification Numbers:}

$$
\text { M3, M31 }
$$

\section{Key Words:}

Empathy; Reliability; Responsiveness; Tangibility; Assurance

\section{Introduction}

Customer Service providers are under the notion that the company's technical perspectives and internal marketing activities are the commitment to the customers' service quality. But in the customer's point of view the company lacks in providing the expected quality service to the customer. The resources of the Airliners' are used for organizational objectives, such as sales improvement, profit maximization, or maintenance and increase of market share in Airline company The resources of the service providers are focused on organizational objectives such as sales maximization and profit maximization or maintenance and increase of market share. The Management Commitment of the company towards service quality to customer is very important to satisfy the tastes and preferences of customer.

The global economy is based on the operations and impacts on related industry such as tourism and manufacturing of aircraft which in turn dependent on the airline industry worldwide - which provides quality service to customers from all corners of the world. Keeping in view the transport services provided by airline Industry worldwide, very few other industries generate the amount and intensity of attention given to airlines. US Government tried to reduce the pressure on airline industry by deregulating of its airlines in 1978 and economic involvement of private players intensified the competition in airlines industry. The same was adopted by rest of the world to deregulate the airline Industry by various governments which helped the Industry grow competitively faster than during the regulated period before 1978 .

Lot of Low-priced airlines and new entrants served to the expectations of the public making possible the air experience to mass targets by providing low-priced services and best in class travel. Even as the low priced competition picked up, there were worries of maintenance standards that may be affected though, which were not statistically evident and even the airline safety was maintained without deterioration.

The demand for national economic development, advancement of Technology and globalization, the business climate and deregulation of airline transportation Industry by Government of India brought in the new competitors into the arena of airline companies which brought the competition to Indian Airlines. There is an atmosphere of competition in the Indian airline services market. Already some airlines started using market gimmicks like offering special discounts and refunds etc., to attract the Customers - This automatically created a better atmosphere for providing better and quality services to the customers. Customer Services in Airlines - The customer centric approach preached and practiced by "Carlzon" which says that "we have reoriented ourselves to become a customer driven company, a company that recognizes that its only true assets are satisfied customers, all of whom expect to be treated as individuals, and who won't select us as their airline unless we do just that" was little practiced by airlines. As per the Skytrax ratings it is quite evident that 
there is a disconnect from customers especially in North America. Customer Services mainly depend on two closely related things i.e. "quality of service expected and quality of service experienced". The expectation of service quality by the customer and his experienced service perception, the quality delivered by different airline service providers are to name a few. The problems related to operations and cost escalation has changed the focus of Airliners from the above named customer service quality, experienced service quality which resulted in customer's dissatisfaction and forcing customers to switch from one airliner to other airliner which can give both the price satisfaction, good travel experience and service quality.

The frequent flyer programs implemented for building customer relationship by airlines are now becoming bane for customers. Customer getting only a restricted selection of airlines tickets for those who are loyal and redeems his or her points. If you try to transfer the points to your spouse, they will have a nightmare experience. The focus of most of airlines has not been on the Customer experience can be seen from the loss and mishandling of baggage or frequent loss, is major source of customer dissatisfaction. There is a loss or mishandling of baggage when compared to European airlines in terms of on-time arrivals ( $73.4 \%$ vs. $67.2 \%)$, but the comfort to consumers is very little.

\section{Customer Orientation in Services}

The customer is treated as being number one in an organizations success these days. Customer service is considered to be of top priority and paramount importance which in the organization. The management commitment for the success should be by providing topnotch customer service is the view of organizations around the world. The executives are now concentrating on the following tangible efforts for delivering superior services to the customer to build customized organizations and sustenance in the market

- Identifying and courting those customers who most closely fit the company's core competences and who bring most of the company's bottom line.

- Retaining existing customers, as opposed to merely chasing new business.

- Enhancing and cultivating employee satisfaction.

- Using a variety of research tools and information sources to listen to customers and develop a deeper understanding of their expectations.

- Using technology to gather, analyze, and quickly disseminate customer information throughout the organization.

- The service leaders share the view that service is more than nice to offer to customers: and what is the most effective way to differentiate them in a competitive market place. One needs the feedback from the day to day transactions-focused, real-time environment through which the management can assess what the company's customer's think and feel about the services offered and only by service performance by getting and disseminating feedback accurately from time to time to your employees', this can be achieved.

- To differentiate the services in the market place one has to at regular intervals select randomly some customers, contact them for short interviews. The customers are to be asked about their recent product purchased from the airliner or service experienced through which you will get quantitative information and qualitative feedback. If trained interviewers are entrusted such work, they will uncover any unresolved problems that can be notified immediately and implemented by the company.

The above steps will make the managers to achieve the goals by getting the desired feedback which can be put to use through the following: Provide the marketing advantage to the company as the customers would be interested in the company, if the company is taking action on their feedback. If there are any issues related to the services provided by the company which are termed as 'service execution issues' - these issues can be corrected, then and there day to day the issues related to 'service delivery' can be taken care of. To see how best you can enhance 'service value' to your customers.

\section{Need for the Study}

Customers "expected quality of service" and their "experienced or perceived quality" is closely related. The "service quality expected by the customers' is the first to be studied and next comes that what he perceived about the quality of service he received or experienced. It is only through the experiences of the people that an assessment can be made about the quality of services provided by a particular airliner company. Customers' satisfaction or dissatisfaction can be identified by finding out the expectations of the airline service users only. The Airliner company managements are of the view that they are meeting to the service quality expected by the customer's needs and wishes, though their views are based on the company's technical and internal perspectives, actually when viewed from the customers' point of view the 'service provider' is lacking. The resources available to the management are to be utilized for the organizational objectives, which are sales, profits or maintaining market share. Unless the 'Service Provider' Airliner Company takes initiatives to set internal quality, it will not be in a position in enhancing service quality which will affect the company's performances. In view of this a large research scope existed on the Service offerings of Private airlines which are fairly new in India. There are six domestic airline companies in India which are considered to be the main players, hence these six airlines namely $A I R$ INDIA, JET AIRWAYS, INDIGO, SPICE JET, GO AIR and KINGFISHER are considered for this study. The majority of people in India travel by these six airliners as per Director General of Civil Aviation Reports 2011, is the main reason for consideration of these airlines for the study. In the said airlines both low priced to full fare airlines are there hence, services in domestic arena have one of the potential research possibilities and therefore the present study is an attempt in this direction.

\section{Objective of the Study}

To examine the perceptions on Service quality to the Customer Satisfaction level in the domestic airline industry in India.

\section{Methodology}

Primary and Secondary data was collected for the study. A quantitative approach is adopted by administering a schedule among the respondents for primary data to evaluate the quality of service provided by the domestic airliners' in which they have traveled, the perceived service quality of each variable was measured through questions designed on a 5 point Likert scale ranging from Very poor (1) to Excellent (5). The questionnaire was administered to 600 customers/passengers during the arrival departure of the flights of six domestic airlines viz: Air India, Jet Airways, Indigo, Airlines, Spice jet Airlines, Go Air Airlines and Kingfisher Airlines, the data was 
recorded and applied Factor Analysis Method, Chi-square test and Cronbach's Alpha test in statistical analysis.

\section{Tools for Analysis}

Factor analysis - principle component analysis was applied. Chisquare test and Cronbach's Alpha test are used as Tools for Analysis. The data pertaining to Airline Industry from year 2000 to 2011 is considered for the study. The collection of data is carried during the months of April - June 2011.

\section{Review of Existing Studies}

A great deal of the researches conducted in recent years in this field of Airline Services and the service offerings by the airlines relating to the eight Ps of the Services Marketing. Examination of literature with regard to the Service offerings can be organized into two things i.e. "Customers' satisfaction" or "dissatisfaction". The service attributes that are of main concern which can be included as part of the study are:

"Timely departure of the aircraft, safety provided by the airliner, competitive (cheaper) airfares, service differentiation, anywhere booking easy availability, varied flight schedules and quality of services offered" apart from baggage handling and in-flight services.

The following is the review of the existing studies relevant to the present research study:

Brent Bowen, E. Headley, Chien-Tsung Lu [1] conducted a research on the airline service performance with multiple selected criteria pertaining to air travel consumers is measured with a tool, i.e. "Airline Quality Rating(AQR)". Various governments utilized this method in decision making and service quality measuring. The bench marking technique was introduced in this article and this method of bench marking technique, Charts and results, the AQR data collection and calculation helped the major US airlines domestic operators to track comparative service quality.

Raquel Espino, Juan Carlos Martín [2] A study conducted using a "Stated Preference(SP) Experiment" which analyses the Individual's preference for the main attributes defining the service offered by the airlines. In this Experiment consistent specifications for "Multinomial Logit" and "Mixed Logit" models are found out. In the first multinomial logit model- all the modeling variables enter in the utility function in linear form. The second multinomial logit model accounts for systematic taste variation including some interactions of socioeconomic variables with level-of-service attributes. As per the experiment results the willingness to pay using mixed logit models are lower than those obtained from multinomial logit specifications implying that preference heterogeneity needs to be considered in order to properly estimate the willingness to pay measures for service quality changes because if taste heterogeneity is important and neglected, the willingness to pay measures can be highly overestimated.

Myungsook an A E Yonghwi Noh [3] conducted a study on the inflight service quality preferred by the two classes viz: prestige (business) class versus economy class were studied. The two factors studied are the "Customer Satisfaction and Loyalty". With respect to seat class - prestige class the six service quality factors of importance are: "alcoholic or non-alcoholic beverage responsiveness and empathy, presentation style, reliability and assurance" were of importance, whereas in Economy class the important service quality factors found were "responsiveness and empathy, food quality, alcoholic beverage, non-alcoholic beverage and reliability" implying that the airline companies may adopt different service delivery strategies basing on the customer seat class.

Robert Bacal [4] Conducted a study on "customer service experts" for improving customer service measuring or metrics is of not much importance but this measuring and metrics do go a long way in improving and building up great service and contribute to improvement of service. To bring about change in the Service Organization the measurement and metrics are organizationally important.

Giovanni Bisignani [5] Report on trend analysis made on the situation of global airline industry taking into consideration the current situation of the Industry and a forecast for the future. The airline industry incurred an estimated loss of $\$ 9.9$ Billion in 2009 . The figures released by IATA in June 2010 suggests $\$ 2.5$ Billion net profits during 2010 which amounts to about $0.5 \%$ profit margin which is half that during the peak levels and far below cost of capital as per IATA Forecast in June 2010 [6]. The company's returns on investments if they continue to be below the cost of capital - eventually the companies making losses will exit the market which in turn provides opportunities to Low Cost Carriers (LCC's) as they have generally reported higher levels of profitability.

Existing studies reveals different aspects of Services in Airlines Industry across the globe. Airline Industry in India being very lately privatized and the skies opened to private players, the scope in the services offered in private airline Industry in India which is fairly new enough and in this, Airline Industry in India has come a long way by quickly building the brands by offering the premium world class services with the objective of offering air travelers in India and guests from abroad, an un-paralleled flying experience, whether the "customer being offered the responsiveness by the companies with speed and as per the needs of the customer" the research is carried out on the five service variables, the effect of commitment to quality services by airline operators and the differentiation of services with respect to Six airlines as there is no such extensive study carried out in this area the topic was chosen for the study. The present study is an attempt in this direction $[7,8]$.

The following is a review of various select airlines chosen for the study on the services offered by each airline to the customers.

The most recognized airliners from India globally and designated airline of India Internationally is "AIR INDIA" and its code is "AI" which is prepared using the merged features of both Air India and Indian Airlines.

Jet Airways flies regular flights which operate forty-four key sectors from Bangalore to all parts of the country. Jet Airways is a budget provider in India and treated as one of the six airlines, doing well in private sector as per reports of DGCA India, runs only one low cost class allowing itself efficiency and easy maintenance. It is an international airliner who entered into Indian Domestic market and presently flies to nearly 60 destinations that span the length and breadth of India apart from international destinations $[9,10]$.

Spice jet Airline: This airliner has catered to the needs of economy class and ideally suited for short medium haul flights which is Go Air's Airlines came up with a variety of options, designed the ticketing system to be very accessible to end passenger basing on the research carried out on the distribution network and thorough evaluation of the media availability. 
Indigo Airlines is the new entrant into the Indian airline market with affordable low cost fares and providing excellent service to the passengers targeting the masses with its cheap prices operates across India with over 147 daily flights. The sector operates flights across length and breadth of the Country. This carrier endows uniquely smooth, safe and pleasant journey.

Kingfisher Airlines operates its flights both domestic and internationally. It was operating the highest number of flights i.e. 400 flights daily with 77 destinations. Kingfisher has a five star rating from Skytrax which is one of the six top airlines having five star rating for the services it offered. During February 2008 this airline had 9,04,000 passengers which gave this company the highest market share in India $[11,12]$.

\section{Customers' perception in indian airline industry}

A schedule designed with a set of over 50 variables and responses of 600 customers traveling on a cross-section of six different domestic airlines was collected and the data is subjected to quantitative analysis by using the statistical analysis tools of factor analysis, chi-square test and cronbach's alpha methods.

As per the study the following are the perceptions of the customers of select airlines of India.

\section{Perception of customer on ticketing formalities - (airline wise)}

The calculated value of chi-square is 3.200 the probability value ( $p$ value) of 0.000 . Therefore there is significant difference between the select airlines customers' perceptions on ticketing formalities reflecting that no specific ticketing formalities are preferred by the passengers traveling in these airlines, the highest rating of $38.2 \%$ to Indigo Airlines and $13.3 \%$ the least rating to Jet Airlines implying Indigo Airlines is more preferred airline on ticketing formalities $[13,14]$.

\section{Customers' perception on flight schedules in select airlines:}

The calculated value of chi-square is 3.463 ; the probability value ( $\mathrm{p}$ value) of 0.000 . Therefore there is significant difference between the airlines customers' perceptions on "flight schedules" - reflecting that the highest rating of $54.8 \%$ to Kingfisher Airlines and $11.7 \%$ the least rating to Spice Jet Airlines implying Kingfisher Airlines is more preferred airline on "flight schedules" [16].

\section{Passengers' perception on the "transport facilities provided" by select airlines:}

The calculated value of chi-square is 2.335 , the probability value ( $\mathrm{p}$ value) of 0.000 . Therefore there is significant difference between the select airlines customers' perceptions on "transport facilities provided" - reflecting that the highest rating of $38.2 \%$ to Indigo Airlines and $2.2 \%$ the least rating to Air India Airlines implying Indigo Airlines is more preferred airline on "transport facilities provided" [17].

\section{Individuals' responses on "cancellation and alternative arrangements" made by different airlines}

The calculated value of chi-square is 2.371 , the probability value ( $\mathrm{p}$ value) of 0.000 . Therefore there is significant difference between the select airlines customers' perceptions on "cancellation and alternative arrangements" - reflecting that the highest rating of $54.8 \%$ to Kingfisher Airlines and $6.4 \%$ the least rating to Spice jet Airlines implying Kingfisher Airlines is more preferred airline on "cancellation and alternative arrangements" [18].

\section{Passengers perception on "catering facilities and hygienity" offered by different airlines}

The calculated value of chi-square is 3.753 , the probability value ( $p$ value) of 0.000 . Therefore there is significant difference between the select airlines customers' perceptions on "catering facilities and hygienity" - reflecting that the highest rating of $58.8 \%$ to Indigo Airlines and $0 \%$ the least rating to Air India Airlines implying Indigo Airlines is more preferred airline on "catering facilities and hygienity" [19].

\section{Passengers' responses on “personalized services" provided by different airlines}

The calculated value of chi-square is 5.481 ; the probability value ( $\mathrm{p}$ value) of 0.000 . Therefore there is significant difference between the select airlines customers' perceptions on "personalized services" reflecting that the highest rating of 58.8\% to Indigo Airlines and $4.1 \%$ the least rating to Jet Airways implying Indigo Airlines is more preferred airline on "personalized services" [20].

\section{Customers' perception on "cleanliness and sanitary conditions" on different airlines}

The calculated value of chi-square is 2.263 ; the probability value ( $\mathrm{p}$ value) of 0.000 . Therefore there is significant difference between the select airlines customers' perceptions on "cleanliness and sanitary conditions" - reflecting that the highest rating of 38.5\% to Kingfisher Airlines and $14.1 \%$ the least rating to Air India implying Kingfisher Airlines is more preferred airline on "cleanliness and sanitary conditions" [21].

\section{Customer responses on the provision of "reading material" airline-wise}

The calculated value of chi-square is 2.764 ; the probability value ( $\mathrm{p}$ value) of 0.000 . Therefore there is significant difference between the select airlines customers' perceptions on "reading material provided" reflecting that the highest rating of $38.2 \%$ to Indigo Airlines and 5.4\% the least rating to Air India implying Indigo Airlines is more preferred airline on "provision of reading material" [22].

\section{Customers' responses on "affordable and reasonable pricing" by different airlines}

The calculated value of chi-square is 3.277 the probability value ( $\mathrm{p}$ value) of 0.000 . Therefore there is significant difference between the select airlines customers' perceptions on "Price charged by the Airline is reasonable and affordable" - reflecting the highest rating of $54.8 \%$ to Kingfisher Airlines and $0 \%$ the least rating to Air India implying Kingfisher is more preferred airline on "affordable and reasonable pricing" [23]. 


\section{Customers responses on "Communication channels related to Price, Promotion and distribution factors" offered by different airlines}

The calculated value of chi-square is 2.890 ; the probability value ( $\mathrm{p}$ value) of 0.000 . Therefore there is significant difference between the select airlines customers' perceptions on "Communication channels related to Price, Promotion and distribution factors"- reflecting the highest rating of $58.8 \%$ to Indigo Airlines and $8.2 \%$ the least rating to Jet Airways implying Indigo Airlines is more preferred airline on "Communication channels related to Price, Promotion and distribution factors".

\section{Customers' perception on "brand loyalty basing on consumption experience"}

The calculated value of chi-square is 3.977 ; the probability value ( $\mathrm{p}$ value) of 0.000 . Therefore there is significant difference between the select airlines customers' perception on "brand loyalty basing on consumption experience"- reflecting the highest rating of $58.8 \%$ to Indigo Airlines and 2.2\% the least rating to Air India implying Indigo Airlines is more preferred airline on "brand loyalty basing on consumption experience".

\section{Customers' perception on “ambient factors” provided by different airlines}

The calculated value of chi-square is 2.583 ; the probability value ( $\mathrm{p}$ value) of 0.000 . Therefore there is significant difference between the select airlines customers' perception on "ambient factors at booking office, airport, onboard are very pleasant"- reflecting the highest rating of $38.5 \%$ to Kingfisher Airlines and $0 \%$ the least rating to Air India implying Kingfisher Airlines is more preferred airline on "ambient factors at booking office, airport, onboard are very pleasant".

\section{Passengers' responses on "behavioral attitude of staff at airport counters \& on board"}

The calculated value of chi-square is 2.880 ; the probability value ( $\mathrm{p}$ value) is 0.000 . Therefore there is significant difference between the select airlines customers' perception on "behavioral attitude of staff at airport counters \& on board"- reflecting the highest rating of $58.8 \%$ to Indigo Airlines and $6.4 \%$ the least rating to Goair Airlines implying Indigo Airlines is more preferred airline on "behavioral attitude of staff at airport counters \& on board" [24].

\section{Passengers" perception on "behavioral attitude - Service Efficiency"}

The calculated value of chi-square is 2.421 ; the probability value ( $\mathrm{p}$ value) of 0.000 . Therefore there is significant difference between the select airlines customers' perception on "behavioral attitude - service efficiency"- reflecting the highest rating of $54.8 \%$ to Kingfisher Airlines and $16.3 \%$ the least rating to Air India Airlines implying Kingfisher Airlines is more preferred airline on "behavioral attitude service efficiency of staff" [25].

\section{Customers' responses on "pricing benefits by removal of in- flight catering service" in select airlines}

The calculated value of chi-square is 2.860 ; the probability value ( $\mathrm{p}$ value) of 0.000 . Therefore there is significant difference between the select airlines customers' perception on "pricing benefits by removal of in-flight catering service "- reflecting the highest rating of $40.0 \%$ to Go Air Airlines and $4.1 \%$ the least rating to Jet Airlines implying Go Air Airlines is more preferred airline on "pricing benefits by removal of in-flight catering service".

\section{Passengers" responses on "benefits of indian airlines merger with air india"}

The calculated value of chi-square is 4.523 ; the probability value ( $\mathrm{p}$ value) of 0.000 . Therefore there is significant difference between the select airlines customers' perception on "benefits of Indian Airlines merger with Air India"- reflecting the highest rating of $67.3 \%$ to Kingfisher Airlines and $11.7 \%$ the least rating to Spice jet Airlines implying with $28.3 \%$ rating to Air India, merger is having little positive effect on passengers' perception.

\section{Passenger responses on "safety and security in national compared to private airlines"}

The calculated value of chi-square is 3.114 ; the probability value ( $p$ value) of 0.000 . Therefore there is significant difference between the select airlines customers' perception on "safety and security in national compared to private airlines"- reflecting the highest rating of $67.3 \%$ to Kingfisher Airlines and $11.7 \%$ the least rating to Spice jet Airlines implying that Kingfisher Airlines is more preferred on "safety and security".

\section{Customers' perception on "deregulation of aviation policy"}

The calculated value of chi-square is 3.024; the probability value ( $p$ value) of 0.000 . Therefore there is significant difference between the airlines customers' perceptions on "deregulation of aviation policy" reflecting the highest rating of $38.2 \%$ to Indigo Airlines and $2.2 \%$ the least rating to Air India implying that the preference of private airlines is higher with $38.2 \%$ to Indigo Airlines, $26 \%$ to Kingfisher airlines, $24.5 \%$ to Spice jet airlines and 23.5 to Jet Airlines and $6.4 \%$ Go Air Airlines.

\section{Customers' perception on "advertising strategies of airlines"}

The calculated value of chi-square is 3.761 ; the probability value ( $p$ value) of 0.000 . Therefore there is significant difference between the select airlines customers' perceptions on "advertising strategies of airlines" - reflecting the highest rating of $58.8 \%$ to Indigo Airlines and $0 \%$ the least rating to Air India implying Indigo Airline is more preferred airline on "advertising strategies of airlines".

\section{Customers' responses on "quality of service rendered by national carrier"}

The calculated value of chi-square is 3.226 ; the probability value ( $\mathrm{p}$ value) of 0.000 . Therefore there is significant difference between the select airlines customers' perceptions on "quality of service rendered by national carrier has enhanced after announcement of economic reforms" - reflecting the highest rating of $40.0 \%$ to Go Air Airlines and $4.1 \%$ the least rating to Jet Airways implying Go Air Airline is more preferred airline on "quality of service rendered by national carrier has enhanced after announcement of economic reforms". 


\section{Customers' perception on "post-sales service”}

The calculated value of chi-square is 3.812 ; the probability value ( $\mathrm{p}$ value) of 0.000 . Therefore there is significant difference between the select airlines customers' perceptions on "post-sales service is pleasant and comfortable" - reflecting the highest rating of $58.8 \%$ to Indigo Airlines and 6.4\% the least rating to Go Air Airlines implying Indigo Airline is more preferred airline on "post-sales services is pleasant and comfortable".

\section{Passengers' responses on "overall rating"}

The calculated value of chi-square is 3.514 ; the probability value ( $\mathrm{p}$ value) is 0.000 indicating that there is significant difference between the airlines customers' perceptions on "overall rating" - reflecting the highest rating of $33.3 \%$ to Indigo Airlines and $7.6 \%$ the least rating to Air India implying Indigo Airline is more preferred airline on "overall rating".

The above are the some of the variables relating to Services Mix (8Ps) of Services marketing viz: Product, Price, Place, Promotion, People, Process, Physical Evidence and Packaging.

As per study the Airlines best conforming to the customers' perceptions are Kingfisher Airlines and Indigo Airlines. On the Product, Promotion, People variables of the services mix Indigo Airlines is leading and on Price, Place and Process variables, Indigo Airlines is in the second position to Kingfisher Airlines whereas on the Price, Place \& Process variables of the services mix Kingfisher Airlines is leading while it is in the second position to Indigo Airlines on Product, Promotion and People variables of the Services Mix. On the Physical Evidence and Packaging variables both are sharing the position equally.

As per the Analysis, Spice Jet airline is having the least rating on 19 service variables and hence it is on the last position of the select airlines in Service Mix variables.

Air India with least rating on 16 services mix variables, hence it is in the fifth position of select airlines.

Jet Airways with least rating on 10 services mix variables; hence it is in the fourth position of select airlines.

Go Air Airlines with least rating on 8 services mix variables is in the third position of select airlines.

As per the Hypothesis tested, the study reflects that there is no conformity between Service Quality \& external Communication on the customer satisfaction level i.e. the satisfaction levels of the customers are not up to the mark as per the customers' perceptions and there is a difference of opinion by the customer with regard to level of satisfaction.

\section{Suggestions}

On the basis of the study, the following are some of the suggestions for improving the quality of services in Airline Industry in a global competitive environment

1. The domestic airline companies must take steps to improve the quality of service by sticking and strictly implementing the five "Servqual dimensions" mainly the "dimensions of assurance and tangibility".
2. The domestic airline companies must take care of not making false promises and stick to what they communicate "External Communication(promotional activities)" like advertising falsely and not conforming to that promises which will have negative impact on the customers' satisfaction.

3. The commitment of Management towards "service quality" must be addressed through leadership. The "work dimension" and 'people dimension' must be carefully promoted depending on which is most required in the context of 'quality service'.

4. The training programs must be targeted on customer contact for evaluation of customer perception on what customer is feeling about the 'service quality' provided and what they expect to be provided - this can be done by training front liners who interact with customers regularly and which is a part of 'Internal Marketing activity'.

5. Top people from Management may be brought to direct customer contact by arranging the people from top management to be present at the airport while the people waiting to board the aircraft, as passengers would be keen and interested or thrilled to meet a person from the Management of the flight they are going to board. Passengers can provide very useful information regarding the services offered by the airlines and which can be of great help in improving and efficiently managing the services with simple adjustments here and there.

6. Employees of the airline may also be brought into contact with customers so as to enable them to understand what they are feeling either just at departure time or arrival time. The involvement of the employees may help the management to understand the pulse of the travelers and with the inputs given by the passengers to the employees so as to build up the best services to be offered to the passengers within the mission, resources and the context of business.

7. Involve the employees in the planning and implementing the Customer Service. Get them involved from start to finish make them understand they are part of the process, take steps to get inputs of what customers needs are and what they want and involve the employees in solving the customer's requirements to their expectations.

8. The top management should take initiatives to show importance to every single customers' service with priority and take steps in such a way that each and every employee to feel responsible to every customers' service and have no exceptions whatsoever. The culture of effectively taking care of every customer's service is to be developed in the company by the leadership.

\section{Conclusions}

This study concludes that: Kingfisher Airlines and Indigo Airlines are the Leaders in the Services offered to the customers with top ratings in the Services mix variables, therefore these two airlines are conforming to the Customer Satisfaction to an extent. The study found that the domestic customers were not satisfied with the customer services offered by the companies in India. It is also found that the companies have not come up to the customers' expectations in fulfilling what the company's had promised regarding the "service quality". The promotional activities were exaggerated and they were not conforming to the customer satisfaction levels which lead to dissatisfaction among customers.

The above suggestions implemented in to and to by the domestic airline companies will make the companies come up to the 
Citation: Malyadri (2014) Service Quality Perceptions of Domestic Airline Consumers in India - An Emperical Study. Int J Econ and Manage Sci

Page 7 of 7

expectations of the service quality by customers and thus excellence in services can be achieved and delivered to the customers, thus improving the companies performances and increased profitability to the companies in a competitive global marketing environment.

\section{References}

1. Chien-Tsung L (2003) University of Nebraska at Omaha, Benchmarking Airline Service Performance-A Reference Point for Airline and Government Evaluation, Brent Bowen, University of Nebraska Omaha Dean E. Headley, Oklahoma State University, Public Works Management Policy January 7(3): 188-204.

2. Raquel E, Juan C, Martín C, Román (2008) Transportation Research Part $\mathrm{E}$ : Analyzing the effect of preference heterogeneity on willingness to pay for improving Service quality in an airline choice context Logistics and Transportation Review, 44 (4): 593-606.

3. Miller JA (2009) Studying Satisfaction, Modifying Models, Eliciting Expectations, Posing Myungsook an A E Yonghwi Noh Airline customer satisfaction and loyalty: Impact of in-flight service quality, 25 June 2009 / published Online: 11 July 2009.

4. Robert Bacal (2010) Myth: Metrics don't create great service. They measure great service that you first Created Kate Nasser September 22nd, 2010.

5. Giovanni Bisignani (2011) Director General \& CEO, International Air Transport Association, Annual Report 2011, 67th Annual General Meeting, Singapore, June 2011.

6. Banfe CF (1992) Airline Management, Englewood Clifts, NJ. PrenticeHall, Inc, 1992.

7. Bitner MJ (1990) Evaluating Service Encounters: The Effect of Physical Surroundings and Employee Responses, Journal of Marketing, 54:246-82.

8. Bolton RN, Drew JH (1991) A Longitudinal Analysis of the Impact of Service Changes on Customer Attitudes. Journal of Marketing, 55:1-9.

9. Brown TJ, GA Churchill, Jr, JP Peter (1993) Improving the Measurement of Service Quality, Journal of Retailing, 69:127-139.

10. Cadotte ER, Woodruff RB, Jenkins RL (1997) Expectations and Norms in Models of Consumer Satisfaction, Journal of Marketing Research, 24: 305-14.

11. Carman JM (1997) Consumer Perceptions of Service Quality: An Assessment of the Servqual dimensions. Journal of Retailing, 66: 33-55.
12. Churchill GA, Suprenant C (1982) An investigation into the Determinants of Customer satisfaction, Journal of Marketing Research, 22: $103-118$

13. Day RL, Taylor SA (1992) Measuring Service Quality: A Reexamination and Extension, Journal of Marketing, 58: 125-131.

14. Gronroos C (1984) A Service Quality Model and Its Marketing Implications, European Journal of Marketing, 18: 36-44.

15. Hui MK, Tse DK (1996) What to Tell Consumers in Waits of Different Lengths: An Integrative Model of Service Evaluation, Journal of Marketing, 60: 81-90.

16. LaTour SA Peat NC (1979) Conceptual and Methodological Issues in Consumer Satisfaction Research, in Advances in Consumer Research. Ann Arbor, MI: Association for Consumer Research, 431-437.

17. H Keith Hunt (1997) Problems and Making Meaningful Measurements in Conceptualization and Measurement of Consumer Satisfaction and Dissatisfaction., ed, Cambridge, MA: Marketing Science Institute, 72-91.

18. Panneerselvam R (2008) Research Methodology, Prentice-Hall of India Pvt. Ltd.

19. Parasuraman A, Zeithamal VA, Berry LL (1985) A Conceptual Model of Service Quality and Its Implications for Future Research. Journal of Marketing, 49: 41-50.

20. Shaw S (1993) Airline Marketing and Management. 3rd edition. Malabar, FL: Krieger Publishing Company, 1993.

21. Spreng RA, MacKenzie SB, Olhavsky RW (1996) A Re-examination of the Determinants of Consumer Satisfaction. Journal of Marketing, 60: 15-32.

22. Subroto B, Pujiono J (1997) Competition among Domestic Airlines, Kelola. 16: 50-61.

23. Sukandi (1996) Differentiation Strategy in PT Merpati Nusantara Airlines (Services differentiation study by implementing service culture). Graduate Thesis, School of Management, University of Indonesia, Jakarta, 1996.

24. Taylor S (1994) Waiting for Service. The Relationship between Delays and Evaluations of Service. Journal of Marketing, 58: 56-69.

25. Teas RK (1994) Expectations as a Comparison Standard in Measuring Service Quality: An Assessment of Re-assessment, Journal of Marketing, 58: 132-139. 